\title{
So the kids are busy, what now? Teacher perceptions of the use of hand-held game consoles in West Australian primary classrooms
}

\author{
John O'Rourke, Susan Main, and Michelle Ellis \\ Edith Cowan University, Perth, Australia
}

\begin{abstract}
Games technology in the form of hand-held game consoles (HGCs) when focussed on specific academic skill development has the capacity to engage students in learning and in turn produce positive academic results. This current research explores teacher perceptions of the implementation of HGCs to enhance the development of mental maths skills (namely the recall of single digit addition, subtraction and multiplication sums) in nine Year 4 classrooms and, through a series of structured interviews and observations, categorises these educators in terms of their role in the classroom. It was hypothesised that the teaching style would impact on the student's motivation and engagement when using the HGCs, however, it became evident that by maintaining set classroom structures the HGCs appeared to have the capacity to engage and motivate students, regardless of the approach of the teacher.
\end{abstract}

\section{Introduction}

In 2001 Prensky suggested that the days of the sage on the stage are over, and that today's classroom teachers may need to take on a new role, particularly when embracing digital technologies (Prenksy, 2001a, p. 347). A decade later it is worth considering whether classroom teachers have progressed in terms of engaging digital natives (Prensky, 2001b). Jukes, McCain, and Crockett (2010, p. 96) ask "have classroom teachers developed the necessary 'new mindset' that places digital tools as central in young peoples' lives?" Greenhow, Robelia, and Hughes (2009) question whether classroom teachers are aware of how students use digital and online technology and how these could be employed in schools in meaningful ways; all at a time where the recognised attitudes and aptitudes of their class members (Oblinger, 2004) necessitate a change of thinking.

Tapscott (2009) claims that a whole generation of students may be learning more outside of school than they are in school and, in a survey of over 2000 American youth aged 8-18, Roberts, Foehr, and Rideout (2005) found that on average they are exposed to 6.5 hours of "new" media each day. Outside of the classroom, many of today's students appear to be empowered and stimulated (Palfrey \& Gasser, 2008) and have control over their lives in a way that is challenging and often times amazing for older generations. In Australia, 96\% of 9-11 year olds and 98\% of 12-14 year olds used the Internet (Australian Bureau of Statistics, 2012), while an estimated $79 \%$ of 5-8 year olds connected to the Internet during 2009 (Australian Bureau of Statistics, 2012). In recent times, Green, Brady, Olafsson, Hartley, and Lumby's (2011) study of Australian students aged 9-16 years and those from 25 other European countries found that Australian children used mobile technologies, such as iPod Touch, mobile phones or Blackberry, to go online more frequently than their European counterparts (31\% vs. 9\%). It is interesting to note that Australian students also used the Internet more frequently at school (96\% vs. $63 \%$ av.) compared to the 25 European countries in the study. Arguably, students are developing new skills through social networking, and harnessing Internet technology to access, store and interact with digital material; however, the type of online activities that students were engaged in the Green et al. (2011) research was not discussed. What is suggested by these figures is that schools, through their sometimes rigid structures and strict frameworks, may not be contributing much to this 'new skill' development.

The present study explores the juxtaposition that exists between students' existing awareness of digital technologies and teachers' capacities to harness this knowledge by using appropriate digital learning tools in the classroom. The perceptions of classroom teachers on employing digital tools in their classrooms and the types of behaviours they engage in as facilitators of learning is the focus of this paper and is part of a much broader study measuring academic outcomes of hand-held game console (HGC) use. In addition, the authors previously explored the use of HGCs in a small scale study focussed on developing mental maths skills for middle primary school students (Main \& O'Rourke, 2011). It became apparent 
using video analysis, classroom observations and interviews with teachers, that the use of HGCs was both well received by the teachers in the pilot study and highly engaging for class members. Given current thinking by those focussed on student learning in the digital age such as, Jukes et al. (2010) and Prensky (2010), an exploration focussed on the instructional processes employed by classroom teachers using HGCs should provide insight into the pedagogy required in classrooms when using games technology. Well structured, supported and purposeful research involving a variety of classrooms using games technology is limited and the following study contributes further to our understanding of this area, particularly relating to Western Australian schools.

\section{The teacher's role when using computer games}

The use of computer games for educational purposes by teachers, sometimes referred to as digital games based learning (DGBL) (Prensky, 2001a), has been recognised as an approach that takes advantage of the current generation's interest in digital technology. Electronic games have often appeared at odds with rigorous academic skill development, and seen as "edutainment" in many circles (Kearney, 2005), but the case for implementing them in specific learning domains is growing (Rosas et al., 2003). Annetta, Holmes, Minogue, and Cheng (2009) suggest today's game technologies are engaging and adaptable to almost any subject; and they generally involve completion of tasks located slightly above the acquired skills of the user making them ideal situations to establish flow. Flow tends to occur when individuals are "fully involved in overcoming a challenge that is just about manageable" (Csikszentmihalyi, 1997, p. 30).

The evidence of efficaciousness of computer games has been explored in a variety of settings, using various forms of digital technology in recent academic literature. For example, Ke (2008) used a series of web-based games to develop Year 4 and 5 students' maths abilities, metacognition and positive attitudes towards maths. Further, Rosas et al. (2003) implemented specifically designed video games in disadvantaged schools in Chile for Year one and two students and focussed on measuring the impact on learning in maths, spelling and comprehension. Annetta et al. (2009) used a teacher created video game to explore the engagement and learning of high school students in the area of genetics. Denner, Werner, and Ortiz (2011) explored the use of specifically designed computer games created by middle school girls to enhance the understanding of science concepts. Finally, Guillen-Neto and Aleson-Carbonell (2012) tested the use of a specifically constructed video game for the purpose of teaching intercultural business communication between native Spanish and English speaking university students. All of these studies highlighted increases in engagement and motivation for learning, academic skill development and, in the case of Ke (2008), improved attitudes towards the targeted subject area.

As much as the evidence towards the effectiveness of DGBL for specific purposes grows, it is teachers and school administrators who will determine (on the basis of available funds and willingness to change pedagogy) how widespread the usage becomes (Tapscott, 2009). Several extensive reports have been commissioned in Europe exploring DGBL and, while without a specific focus, the authors of these reports examined how teachers perceived the impact on their classroom roles when using digital technology. For example, Groff, Howells, and Cranmer (2010) examined the impact of HGCs in Scottish schools and reported that the teachers' role changed when implementing them in their classrooms. The role changes included interacting with their students more, spending less time at the board, seeing themselves more as facilitators, involving the students more in decision making, letting go of their central role, becoming more information technology (IT) oriented, and becoming more creative and reflective by stepping back and observing the learning rather than controlling it all.

Further, in a survey of over 200 teachers using DGBL in European schools Wastiau, Kearney, and Van den Burge (2009) concluded through teacher feedback that the most important impact of games technology in the classroom was on students' motivation to learn, supporting students with additional needs, developing initiative and persistence (and other personal skills), and developing spatial and motor skills (p. 46). However, less than 25 percent felt they enhanced actual student performance and skill development. This type of thinking may be one reason that teachers rarely implement games technology in the classroom. Other difficulties experienced by teachers, as identified by Groff et al. (2010), when implementing games technology for the first time, were; feelings of panic about using digital tools, concerns about the teacher's role, queries of the relevance of the learning, classroom organisation, uneasiness with new technology in a busy curriculum and fears about parental perception. More 
positively Groff et al. (2010) observed that the more experienced teachers were with DGBL the less they held these reservations.

Whether the needs and capabilities of students in this current age are intrinsically different to learners of other generations has been debated in the academic literature (Baurelein, 2008; Bennet, Maton, \& Kervin, 2008; Prensky, 2006; Tapscott, 2009); but given the widespread use of IT by this current generation it corresponds that teachers should envisage today's classrooms as different to their own. While specifically targeted DGBL such as HGCs appear well suited for today's learners, before school administrators and classroom teachers are prepared to implement it, researchers must continue to provide empirical evidence that these approaches are effective with students and positively received by educators. A small scale study by Miller and Robertson (2009) and initial research by Main and O'Rourke (2011) highlighted significant differences in speed and accuracy of mental math recall and student self-concept between students that used a HGC and Dr Kawashima's Brain Training and those who used their normal routine for mental math skill development. While it would be folly to make generalisations from these small-scale studies, Miller and Robertson's (2011) recent research involving 634 primary aged students (ages 10-11) from 32 locations throughout Scotland provides clearer evidence of the benefits for students using this technology. In this research students gained $50 \%$ more in speed and accuracy in mental maths using the HGC compared to the control group engaged in their normal routine.

In response to these positive findings the research presented herein explored the use of HGCs with 258 students in nine Year four/five mathematics classes using Dr Kawashima's Brain Training. The aspect of the study presented here was whether using digital technology inspires teachers to adopt classroom approaches that differ from traditional classroom practice; and whether teachers in Western Australian classrooms are ready to embrace more student-centred ways of learning, working as the guide on the side rather than the sage on the stage.

\section{Method}

Eight Year 4 and one Year 4/5 classrooms were involved in a randomised controlled trial over a school term. Students in the experimental classrooms utilised Nintendo DS lites and used the COTS software program, Dr Kawashima's Brain Training for 20 minutes each day to develop mental maths skills. Brain Training involves several maths related computation games; focussed on speed and accuracy. The classes involved in the study focussed at least half their daily sessions on the $\mathrm{x} 20$ game, in which random single digit addition, subtraction and multiplication sums appear on the screen. Students enter their answers using a stylus on the HGC touch screen and are given a time and game speed (for example 'walking speed' or 'rocket speed' for completing the sequence under 10 seconds) on completion of a set. After they had completed the $\mathrm{x} 20$ session, students were free to choose from several other games. These included; $\mathrm{x}$ 100 random single digit sums, Head Count (quick addition and subtraction of people entering and leaving a house), low to high (memorising the position of number presented and recall), syllable count (counting syllables in well known phrases), Sudoku (using logic to fill in missing numbers on a grid) and others. All students set goals for speed or accuracy at the beginning of each week and reviewed these (with their teacher) at the end of each week. An engaging element of Brain Training is that the more sessions students play the more games become available i.e., all new players start with limited games (such as $\mathrm{x}$ 20 ) and this increases to provide the full range over time.

Those students in the non-experimental classrooms completed mental maths lessons utilising more traditional methods (i.e., teacher modelling and explanations, drill and practice strategies, completion of mental maths worksheets, etc.). In the interest of equity the control classes utilised the HGCs in the following term.

This study replicates similar research conducted in Scotland by Miller and Robertson $(2009 ; 2011)$ and a small scale pilot study completed by Main and O'Rourke (2011). The difference between this study and earlier research was that, through a series of semi-structured interviews and set observation periods, teacher behaviour was monitored and viewpoints on using this form of technology were ascertained. It offers, for the first time, the perceptions of Australian classroom teachers on the use of HGCs in primary classrooms and the pedagogy that facilitates their implementation. To sum up, the research questions for this current study were; 
1. Do teachers perceive the use of HGCs in the classroom as an effective learning tool in mathematics?

2. Do classroom teachers perceive students' participation as being different when they are using HGCs?

3. Do classroom teachers perceive their role in the classroom as being different when students are using HGCs?

\section{Participants}

Two hundred and fifty-eight Year 4/5 children (aged between 9 and 11 years) from a middle to lower socio-economic demographic in the Perth metropolitan area participated in the study; principals of their schools had responded to a request following a conference presentation (see Main \& O'Rourke, 2009) and an article in the largest selling West Australian daily newspaper (Hiatt, 2009). The schools involved were mainstream primary schools, four of which were public and three of which were Catholic schools. The classes engaged in the research were taken by seven teachers (two teachers were utilised on two separate occasions with different classes). The seven teachers, two males and five females, represented a cross section of teaching experience and approaches. All had little or no experience with using game technologies in their classrooms.

\section{Procedure}

In this research, classroom teachers and teaching staff met members of the research team and were given clear guidelines on the protocols for utilising the HGCs (see Appendix). Teachers were given a HGC at least six weeks prior to implementation in the classroom, to assure a level of familiarity. As a result most were aware of how the HGC operated and the different aspects of Brain Training. A member of the research team visited the classroom on day one of the intervention and assisted students to set up their individual profiles on the HGCs within the Brain Training software.

A research assistant or member of the research team visited each classroom on at least four occasions during the term to observe and interview participants. Interview questions were focused on identifying the teacher's knowledge of HGCs, their opinions on HGCs as learning tools, student enjoyment of HGCs, changes in attitude to mathematics, concerns and apprehensions about using this technology, opportunities imagined with the HGC, and changes in teaching roles as a result of implementing the HGCs.

Teacher responses were recorded and transcribed directly by the research assistant and additionally by a dictating service. These interviews were examined for common themes using the open coding method established by Strauss and Corbin (1998) (in which labels are made in the margins of interview transcripts; see Table 1).

Table 1

Common themes established using a line by line analysis of the interview transcripts

\begin{tabular}{lll}
\hline Interviewer: & $\begin{array}{l}\text { What sort of behaviours are you seeing while they're using } \\
\text { the HGC? }\end{array}$ & \\
\hline Teacher: & $\begin{array}{l}\text { Most of them are focussed on what they are doing; some of } \\
\text { those students who normally it takes a while for them to } \\
\text { actually focus on something are getting into it quite } \\
\text { quickly. }\end{array}$ & $\begin{array}{l}\text { CODING } \\
\text { independence } \\
\text { motivation }\end{array}$ \\
\hline
\end{tabular}

Additionally, classes were observed using the HGCs by the research assistant on three separate occasions during the research intervention. During these occasions the research assistant, who was an experienced classroom practitioner, sat in the corner of the classroom and recorded classroom events at five minute intervals. Detailed notes on student behaviour, teacher-student interactions, and classroom structures and protocols were recorded. While their teaching styles differed, regular visits by a research assistant highlighted that all teachers implemented the HGCs with ease and maintained research protocols 
throughout. Given the consistency of the interviews and observations, an emerging view of the classroom teachers' thoughts on this technology and their own classroom styles became evident.

\section{Results}

The interview transcripts provide a vehicle to establish a deeper understanding of the manner in which teachers implemented game based technology in the classroom and its impact on traditional student roles. It is important to note that the students in this current research were only in Year 4 , but this is the generation that have grown up in the digital era and as such were more familiar with this technology than their classroom teachers.

\section{Do teachers perceive the use of HGCs in the classroom as an effective learning tool in mathematics?}

All teacher interview data were examined for key themes (see Table 2). Overwhelmingly, the teacher views were positive and they accepted the $\mathrm{HGC}$ as an aid in the classroom.

Table 2

Teacher's response to using HGCs for maths

Themes of semi-structured interviews with teachers: responses to questions.

\begin{tabular}{|c|c|c|}
\hline & Theme & $\begin{array}{l}\text { Frequency of theme } \\
\text { suggestion }\end{array}$ \\
\hline \multirow[t]{2}{*}{ Positives } & - Students are motivated and engaged. & 29 \\
\hline & - Students problem solve. & 7 \\
\hline \multirow[t]{5}{*}{$64.4 \%$} & - Students make choices. & 10 \\
\hline & - Students set realistic goals. & 6 \\
\hline & - Students are more independent - less teacher focussed. & 8 \\
\hline & - Students collaborate more. & 10 \\
\hline & - Assists student organisation. & 6 \\
\hline Challenges & - Students can use HGC for unintended purposes. & 4 \\
\hline $13.7 \%$ & $\begin{array}{l}\text { - Students can be overly individualistic and focussed on } \\
\text { best scores only. }\end{array}$ & 6 \\
\hline Things to think & - Time allocated to DS can extend into other maths lessons. & 3 \\
\hline about & - Need to individualise usage for some students. & 8 \\
\hline \multirow[t]{2}{*}{$21.9 \%$} & - Need to ensure students focus on specific games. & 3 \\
\hline & - Technology can be problematic. & 2 \\
\hline
\end{tabular}

The most positive outcome, according to all teachers, was that the students were more engaged and motivated, and those who typically were slow to start or were normally disengaged were more inclined to participate when using the HGCs. This comment from a school administrator illustrates this aspect of the study:

Went in and had a bit of a chat and a look at the HGCs in action. Awesome stuff! None of the students wanted to talk to me, as they were all engrossed in the program. Wouldn't even let me play! Even our low achievers were actively engaged.

\section{Do classroom teachers perceive students' participation as being different when they are using HGCs?}

The use of the Nintendo DS placed many of the classrooms teachers in a position where they were unable to provide expertise in the equipment being used and, as Prensky (2001) identified, in digital environments the role of the teacher changes. After the students in one intervention classroom had used the HGC for a short period of time, a classroom teacher describes what he saw;

If one of them sitting next to them in their group knows, they'll Independence 
offer a suggestion as well, so quite often you'll go over there and it's already been sorted out. It's basically just keeping an eye on them.

Guide on the side

Some teachers embraced these interactions, encouraging the student collaborations they observed, such as those students who became the expert in certain games and assisted others to 'play' them. Teachers also allowed students to address the class about both maths and games strategies. These maths strategies were focussed on rules to share with others (e.g., when you multiply any number by 0 it is still 0 ); while game strategies focussed on ways to speed up performance, like writing smaller, looking for game patterns and potential 'cheats'. Teachers also noted a number of positive attributes of participation including students making choices, setting realistic goals and being well organised (see Table 3 for a cross-section of comments).

Table 3

Selection of classroom teacher comments on student use of HGCs

\begin{tabular}{|c|c|}
\hline \multicolumn{2}{|r|}{ Positives when using the HGC } \\
\hline $\begin{array}{l}\text { Students } \\
\text { motivated/engaged }\end{array}$ & $\begin{array}{l}\text { - These kids were very keen. } \\
\text { - The students can't wait to do it. } \\
\text { - Makes learning their tables fun. } \\
\text { - They always remind me of the DS, they never remind me about homework. } \\
\text { - Most of them are very focussed on what they're doing; some of those } \\
\text { children who normally quite often it takes a while for them to actually } \\
\text { focus are getting into it quite quickly. }\end{array}$ \\
\hline Students made choices & $\begin{array}{l}\text { - They also get to choose what they're doing as well, rather than mental } \\
\text { maths off a sheet when everyone has to do the same thing. }\end{array}$ \\
\hline $\begin{array}{l}\text { Students set realistic } \\
\text { goals }\end{array}$ & $\begin{array}{l}\text { - Most of them are setting realistic goals and most of them are quite pleased } \\
\text { at how they're going. }\end{array}$ \\
\hline $\begin{array}{l}\text { Students were well } \\
\text { organised }\end{array}$ & $\begin{array}{l}\text { - I can just keep an eye on them and they go for it. } \\
\text { - They're coming in, they're getting ready, and they're setting themselves up, } \\
\text { so basically when the time starts most of them are ready to go. }\end{array}$ \\
\hline $\begin{array}{l}\text { Students were less } \\
\text { teacher focussed }\end{array}$ & $\begin{array}{l}\text { - It's easy for them to ask the person next to them. } \\
\text { - They are actually working together and other students are offering to help. }\end{array}$ \\
\hline Students collaborated & $\begin{array}{l}\text { - We've got one child who has eyesight problems, so we ended up finding } \\
\text { that we needed to increase the text size. A couple of students actually } \\
\text { found out how to do it before I did. }\end{array}$ \\
\hline \multicolumn{2}{|r|}{ Challenges when using the HGC } \\
\hline $\begin{array}{l}\text { Students focussed on } \\
\text { individual and } \\
\text { competitive goals. } \\
\text { Technical aspects of } \\
\text { using the HGC }\end{array}$ & $\begin{array}{l}\text { - I had two boys in the class that didn't like to fail. When they worked } \\
\text { through their activity, if they felt that they had made too many mistakes } \\
\text { they turned their HGC off to avoid getting a lower result. } \\
\text { - A few of the HGC's froze or didn't work and this was remedied by having } \\
\text { spares to use. }\end{array}$ \\
\hline $\begin{array}{l}\text { Students do not } \\
\text { maintain focus on set } \\
\text { tasks. }\end{array}$ & $\begin{array}{l}\text { - We found out the other day they know how to text between the machines } \\
\text { and they were sending rude words and things, and that's something we } \\
\text { didn't know that you could do - but the students did. }\end{array}$ \\
\hline
\end{tabular}
Do classroom teachers perceive their role in the classroom as being different when students are
using HGCs?

Prior to implementation it was important to establish with teachers that Dr Kawashima's Brain Training was not a tool that taught mental maths strategies; it was simply a game. Its format was engaging and the game elements novel for many students, but beyond this the same challenges that exist when teaching a Year 4 mixed ability class were evident in all classrooms; namely, all students are being challenged to improve their speed and accuracy, some are more ready than others to do so. One of the classroom teachers expressed concern and ensured that students were aware that despite the number of games available there was going to be a strong focus on specific drill and practice games: "I had a talk to (researcher's name) about the low achievers. I really want to encourage them to focus on x 20 and x 100, 
rather than just let them do whatever they choose". Interviews with parents to determine their perceptions on using the HGCs in the classroom indicated that a potential lack of strategic input was a concern for some; "More could be done in spending time with kids getting deep understanding than getting things right with the DS." Concerns of this nature were part of initial discussions with teachers engaged in the research to ensure that all class members were supported and that discussion on mental maths strategies were connected with the Brain Training sessions.

The observation sessions revealed a variety of approaches used by the teachers when the HGCs were employed for their mental maths sessions. Structured protocols, in line with original research from Miller and Robertson $(2009 ; 2011)$ were established (see Appendix) but no guidelines were given as to how the teacher would teach the class. Observations revealed that all classroom teachers had implemented tight protocols for distribution of the HGCs. Students appeared to be aware of whose role it was to hand them out and collect them in an organised and efficient manner. Additionally, students appeared to know which HGCs needed to be charged at the end of the session. But, beyond adherence to structures and general student engagement, all Brain Training sessions varied.

Once the HGCs were implemented in the classroom it became clear that students were engaged and required minimal input from their teachers. It prompts the question: If the students are fully engaged, what now? At face value, one would hope classroom educators could do more than "keep an eye on them" (as suggested in Table 3); but if the class is functioning without their input, the temptation exists to engage in non-teaching related behaviour (e.g., marking, answering emails). Decisions on how to support students and employ strategy discussion in these sessions varied and in many ways defined the style of teaching in the classroom. Some classrooms resembled traditional classrooms with strict adherence to students maintaining their seats during the session. In other classrooms students appeared to have the freedom to move, collaborate and in some instances connect via Bluetooth with each other. Some classroom teachers fostered competition via the posting of record scores, challenges against the teacher, and races in small groups on the $\mathrm{x} 20$; while other classes appeared to be engaged, but not focussed on setting individual time records. While all students were encouraged and observed to set goals, one class focussed on accuracy goals rather than speeds and this was reinforced by the classroom teacher.

In line with discussions presented by Chen (2003) and Smith and Cook (1992) on employing metaphors to describe teacher behaviour, observations revealed that teachers fell into one of the following three categories (see Table 4):

- Category one: The guiding teacher.

- Category two: The facilitating teacher.

- Category three: The interactive teacher.

Chen (2003, p. 24) suggests that employing metaphors such as guiders, facilitators and interactive teachers offer the possibility of identifying "salient teaching roles" and "changing what teachers do in the classroom". Smith and Cook (1992) further highlight that categorising teachers approaches helps to "reduce the complexity and to examine relationships between teaching approach and teaching outcomes" (p. 137).

Two of the seven teachers were categorised as guiding teachers. These teachers observed and supported, but rarely interacted with the students. Observations of these teachers revealed a passive approach; once the class began using the HGCs these teachers remained at their desks. Their classes were very studentcentred and little direction was provided, however, both teachers were observed to be caring and empathetic (praising when appropriate and responding to questions and requests promptly). The students generally completed their sessions with the HGCs independently; with occasional collaborations observed. Descriptions used by the research assistant to describe the teachers' interactions were; observing, assisting, encouraging and intermittently participating. These teachers did not appear overly enthusiastic, nor did they seek to utilise the HGCs beyond set tasks i.e., establish class competitions, or race students themselves. Essentially the students were engaged with the HGCs and these sessions ran smoothly - somewhat akin to a class visiting a computer laboratory.

Two teachers were observed to be facilitators. These teachers engaged and interacted more with the students. They were supportive and, while not altering the class significantly, they intervened when 
required and were enthusiastic and overt in their celebrations of improved performances by students. They often reviewed performances and allowed the class members to provide feedback on strategies that had assisted them. One of the facilitating teachers described her new role thus:

The children took charge of their own learning. However, I still needed to assist those who had problems with their learning as they often became frustrated that they weren't answering the questions correctly or would take so long to complete the $\mathrm{x} 20$.

As much as the class was engaged, positive and enthusiastic it was not dissimilar to a standard class, other than the use of games technology. There was nothing beyond the high levels of engagement and selfdirected student behaviour that would suggest that this class was any different to others. The traditional structures such as the beginning, middle and end components existed. Students waited for both instructions and for the HGCs to be distributed, engaged in the lesson and finished with teacher lead discussions and collection of the HGCs.

Three of the teachers were categorised as interactive teachers. These teachers appeared to be mindful of the opportunities that the use of HGCs provided their classes. They were often sensitive to the variety of needs within the class and often intervened or strategized when students had problems. Some joined in and competed with class members; they, like the students, showed that they appreciated the fun that this technology provided. These teachers appeared aware of what levels their students were at and were often sought out when a student felt they had achieved well. In describing her role an interactive teacher said:

My role as a teacher was very different. I became a photographer of record breakers, a person to share their celebrations. Very few needed my help or supervision. I didn't have to keep kids on task at all.

One interactive teacher was seen to rap with her class to develop the necessary skills for a problematic multiplication table. The classes appeared to be fun, enthusiastic, interactive, engaged and busy.

Table 4

Teacher types

\begin{tabular}{llll}
\hline & Schools 1 and 2 & Schools 3 and 4 & Schools 5, 6 \& 7 \\
\hline Teacher type & Guiding teacher & Facilitating teacher & Interactive teacher \\
\hline \multirow{2}{*}{$\begin{array}{l}\text { Observed } \\
\text { behaviours }\end{array}$} & Observed & Assisted & Competed \\
& Assisted & Redirected & Celebrated \\
& Encouraged & Enthusiastic & Assisted \\
& Minor participant & Unfolded & Promoted \\
& & Celebrated & Intervened with problems \\
& & Participated & Maintained protocols \\
& & Major participant \\
\hline
\end{tabular}

\section{Discussion}

Previous examination of the use of DGBL in classrooms has identified high levels of student engagement (Wastiau et al., 2009) and students seeing this technology as "less work - more fun" may be critical to their improved focus. In this study, the Brain Training program used has a pleasant format, and a range of mathematical games; but it is simply another way of presenting basic maths drill. Perhaps the idea that using a popular form of games technology in the classroom makes the lessons appear like something else (other than normal class work) may make a difference. As identified by a student in O'Rourke, Main, and Ellis (2013) "it seems more like fun than work" and feedback from teachers, parents and students suggested that, overwhelmingly, the experiences were positive.

Another aspect, also identified by Wastiau et al. (2009) in their review of DGBL throughout Europe, was that teachers acknowledged the use of these games fostered collaborations that did not exist before the 
advent of this technology. Teachers commented that students tended to solve problems themselves and appeared happy to assist peers with difficulties. Prensky's (2010) suggestion that digital game playing allows students to work in a familiar realm may partly explain this capacity to be more self-determined. As described by teachers involved in the research, the fluidity of the classes and the choice making that the Brain Training sessions encouraged created a different dynamic than a traditional classroom. In these classes, beyond completing the obligatory x 20 sessions, students would select a variety of different math oriented games and as a result the class effectively individualised their learning. Within this environment, students became confident in aspects of their learning and in many cases shared positive experiences and expertise with peers.

The classroom teachers in this study had clear goals for numeracy performance (as Western Australian schools engage in annual standardised National Literacy and Numeracy Testing [NAPLAN]). As such, the challenge often appeared to be how to tie these sessions in with their general numeracy programs. Despite this, the key observation was that students were engaged to varying degrees, made choices on what they were learning (and were given the freedom to do so) and collaborated and supported each other. The classroom teachers noted that students also made choices on what maths game they would play and were encouraged to do so. In this respect, using the HGC allows classrooms to differentiate their curriculum. The capacity to allow student choice is consistent with research on effective differentiation in classrooms (Tomlinson, 2001) and the principles of a universal design approach to learning (UDL) (Gargiulo \& Metcalfe, 2010). For example, it was observed in one particular classroom that beyond the obligatory x 20 session, several students had specific games that they became focussed on. In this classroom the teacher acknowledged these efforts and took photos of students who had achieved high scores in their favourite game. Some students openly acknowledged that they were slow but steady in the $\mathrm{x} 20$, but had achieved excellent results in the triangular maths or head count.

If the HGC can engage, motivate, and organise learners as often described during interviews (see O'Rourke et al., 2013), what role does the classroom teacher now occupy when using this form of technology? In this research, formulating strategies and supporting students was an important variation in all classrooms. Teachers were observed to begin sessions differently to encourage student performance in their Brain Training sessions; in some classes there were warm-ups where the teacher addressed the class about strategies, and others where the class engaged in a "maths rap" to (as described by the teacher) "fire everyone up". Overall, observations revealed that the classroom teacher was still instrumental in the feel of the classroom.

Prensky (2010) points educators towards the idea of partnering in a digital age; more specifically "letting students focus on the part of the learning process they can do best, and letting teachers focus on the part of the learning process they can do best" (p. 13). For example, students were familiar with the technology and were able to assist each other and extend the manner in which the tools were used, whereas, the classroom teachers provided content and strategic input. But, to truly "create the relevance that is so critical to learning" and to take classrooms using digital technology to new ground, Jukes et al. (2010, p. 53) suggest that "teachers must know the world of their students". If teachers truly appreciated the places that students could go with digital technology and the fun opportunities that could exist, perhaps they could engage and connect with their students in new ways.

\section{Conclusions}

The preceding research describes teacher perceptions of the use of HGCs in primary mathematics lessons and observations of teacher approaches when using this digital tool. Although limited, this research is further evidence that digital technology has the capacity to change the teaching and learning environment. Consistent with previous research using HGCs, teachers were overwhelmingly positive about their use. In general it appeared that it was the HGC's capacity to engage students in sustained learning and collaborative opportunities that most impressed the educators in this research.

In response to the learning environment created by the HGCs, the teachers also engaged in different roles. These roles impacted on the feel of the classroom, but it appears that despite the variation in teacher styles, the students overwhelmingly perceived the use of HGCs as a positive element in their learning environment (O'Rourke et al., 2013). It could be suggested that the technology was "teacher-proof", 
however, the authors would argue that it highlights the need to reconceptualise the role of the teacher to make the most of the learning opportunities provided by this type of technology.

As with any new movement in education some teachers will embrace these changes and others will hold onto more traditional methods - somehow not prepared to let go of the past in case their students miss something that those in their previous classes received. But as Prensky (2010, foreword cited in Jukes et al., 2010) describes, this is potentially an amazing time for students "with new technologies, new sources, and new possibilities...within this context kids teach themselves, follow their own interests, and prepare themselves on their own for the future". How teachers see themselves within this process will continue to dominate thought over the ensuing decades. As was evidenced within this research, some classroom teachers will view the process as a means to achieving traditional learning outcomes like increasing mental maths skills, while there will be others who appreciate that this was only part of what was going on.

While the type of teacher in a classroom implementing digital technology is important, particularly to value added aspects of the curriculum, it would appear that it is not the style of the teacher that is the key factor, rather, it is the choice of instructional tools that the teacher makes. Tools shown to be effective such as HGCs appear to have the capacity to engage and motivate students, regardless of the role played by the teacher. While this study reports on drill and practice usage of HGCs, examples exist of their efficacy in higher order learning with students (Groff et al., 2010). As Jukes et al. (2010) surmise in their view of the teachers role in the digital classroom; we need to design learning tasks that challenge students to engage; allow students access to appropriate tools and resources they will need, and "then, in many cases our job is to get out of their way as they access information in ways that are completely foreign to us" (p. 101). It would appear that students, on the basis of outside school engagement in games technology, are ready to embrace these changes; and teachers will either join them or watch them. Whatever the style of the teacher, instructional decisions based on evidence of what engages today's learners appears paramount in today's classrooms.

\section{References}

Annetta, L. A., Minogue, J., Holmes, S. Y., \& Cheng, M. (2009). Investigating the impact of video games on high school students' engagement and learning about genetics. Computers \& Education, 53, 74-85.

Australian Bureau of Statistics. (2012). Children's participation in cultural and leisure activities (Cat. No. 4901.0). Retrieved from

http://www.abs.gov.au/ausstats/abs@.nsf/Products/4901.0 Apr+2012 Main+Features Internet+and+ mobile+phones? OpenDocument

Baurelein, M. (2008). The dumbest generation: how the digital age stupefies young Americans and jeopardizes our future. New York: Penguin.

Bennet, S., Maton, K., \& Kervin, L. (2008). The 'digital natives' debate: A critical review of the evidence. British Journal of Educational Technology, 39(5), 775-786.

Chen, D. (2003). A classification system for metaphors about teaching. Journal of Physical Education, $74(92), 24-31$.

Csikszentmihalyi, M. (1997). Finding flow: the psychology of engagement with everyday life. New York: Basic Books.

Denner, J., Werner, L., \& Ortiz, E. (2011). Computer games created by middle school girls: Can they be used to measure understanding of computer science concepts? Computers \& Education, 58, 240-249.

Gargiulo, R. M., \& Metcalfe, D. J. (2010). Teaching in today's inclusive classrooms: A universal design for learning approach. Belmont, CA: Wadwswoth, Cengage Learning. 
Green, L., Brady, D., Olafsson, K., Hartley, J., \& Lumby, C. (2011). Risks and safety for Australian children on the internet: Full findings from the AU Kids Online survey of 9-16 year olds and their parents. Cultural Science, 4(1), 1-73. Retrieved from http://culturalscience.org/journal/index.php/culturalscience/article/viewFile/49/129

Greenhow, C., Robelia, B., \& Hughes, J. E. (2009). Web 2.0 and classroom research: What path should we take now? Educational Researcher, 38(4), 246-259.

Green, L., Brady, D., Olafsson, K., Hartley, J., \& Lumby, C. (2011). Risks and safety for Australian children on the internet: Full findings from the AU Kids Online survey of 9-16 year olds and their parents. Cultural Science, 4(1), 1-73. Retrieved from http://culturalscience.org/journal/index.php/culturalscience/article/viewFile/49/129

Groff, J., Howells, C., \& Cranmer, S. (2010). The impact of games in the classroom: Evidence from schools in Scotland. Bristol: Futurelab.

Guillen-Nieto, V., \& Aleson-Carbonell, M. (2012). Serious games and learning effectiveness: The case of "It's a Deal!" Computers \& Education, 58, 435-448.

Hiatt, B. (2009, July 31). Maths stimulus in Nintendo mind games. The West Australian.

Jukes, I., McCain, T., \& Crockett, L. (2010). Understanding the digital generation: Teaching and learning in the new digital landscape. Canada: 21st Century Fluency Project: Corwin.

Ke, F. (2008). A case study of computer gaming for math: Engaged learning from gameplay? Computers \& Education, 51, 1609-1620.

Kearney, P. (2005). Mindless entertainment: A literature review on the use of computer games in education. Paper presented at the Eighteenth Annual Conference of the National Advisory Committee on Computing Qualifications. Tauranga, New Zealand.

Main, S., \& O'Rourke, J. (2009). Yay it's Maths! Using handheld game consoles in a primary classroom. Paper presented at the Catholic Education Office of Western Australia Curriculum Conference 2009.

Main, S., \& O'Rourke, J. (2011). New directions for traditional lessons. Can handheld game consoles enhance mental mathematics skills? Australian Journal of Teacher Education, 36(2), 43-55.

Miller, D. J., \& Robertson, D. P. (2009). Using a game consoles in the primary classroom: Effects of "brain training" programme on computation and self-esteem. British Journal of Educational Technology, 4(2), 242-255.

Miller, D.J., \& Robertson, D. P. (2011). Educational benefits of using game consoles in a primary classroom: A randomised controlled trial. British Journal of Educational Technology, 42(5), 850-864.

Oblinger, D. G. (2004). The next generation of educational engagement. Journal of Interactive Media in Education, (8), 1-18. Special Issue on the Educational Semantic Web. Retrieved from http://wwwjime.open.ac.uk/article/2004-8-oblinger/199

O'Rourke, J., Main, S., \& Ellis, M. (2013). "It doesn't seem like work, it seems like good fun": Perceptions of primary students on the use of handheld game consoles in mathematics classes. Technology, Pedagogy and Education, 22(1), 103-120.

Palfrey, J. \& Gasser, U. (2008). Born digital. New York: Basic Books.

Prensky, M. (2001a). Digital game based learning. St Paul, MN: Paragon.

Prensky, M. (2001b). Digital natives, digital immigrants part I. On the Horizon, 9(5), 1-6. 
Prensky, M. (2006). Don't bother me Mom, I'm learning!: How computer and video games are preparing your kids for twenty-first century success and how you can help! St Paul, MN: Paragon.

Prensky, M. (2010). Teaching digital natives: Partnering for real learning. U.S.A.: Corwin.

Roberts, D. F., Foehr, U. G., \& Rideout, V. (2005). Generation M: Media in the lives of 8-18 year olds. Menlo Park, CA: Kaiser Family Foundation. Retrieved from http://kff.org/other/generation-m-mediain-the-lives-of/

Rosas, R., Nussbaum, M., Comsille, P., Marianov, V., Correaa, M., Flores, P. \& Salinas, M. (2003). Beyond Nintendo: design and assessment of educational video games for first and second grade students. Computers \& Education, 40(1), 71-94.

Smith, D., \& Cook, A. (1992). Teacher education and the principle of uniqueness. South Pacific Journal of Teacher Education, 20(2), 137-146.

Strauss, A., \& Corbin, J. (1998). Basics of qualitative research: techniques and procedures for developing grounded theory (2nd ed.). Newbury Park, California: Sage.

Tapscott, D. (2009). Grown up digital. USA. McGraw-Hill

Tomlinson, C. A. (2001). How to differentiate instruction in mixed ability classrooms (2nd ed.). Alexandria, VA: Association for Supervision and Curriculum Development.

Wastiau, P., Kearney, C., \& Van den Berghe, W. (2009). How are digital games used in schools? Final report of the European Schoolnet, Brussels. Retrieved from http://games.eun.org/upload/gisfull_report_en.pdf

Corresponding author: John O'Rourke, j.o_rourke@ecu.edu.au

Australasian Journal of Educational Technology (c) 2013.

Please cite as: O'Rourke, J., Main, S., \& Ellis, M. (2103). So the kids are busy, what now? Teacher perceptions of the use of hand-held game consoles in West Australian primary classrooms. Australasian Journal of Educational Technology, 29(5), 735-747. 


\section{Appendix}

Protocol for utilising HGCs

\section{Daily}

1. Teacher to bring out HGCs in containers at the beginning of the day from a secure cabinet.

2. Students engage in morning formalities.

3. Individual students to collect HGCs for groups and distribute these to group members.

4. Students to individually use HGCs for at least 15 minutes - 5 minutes may be spent comparing and connecting with peers.

5. Students are allowed to explore the program at will - but emphasis must be placed on the $\mathrm{x} 20$ sums (and $\mathrm{x} 100$ if they require a change).

6. A timer will signal the end of the twenty minute class (at 19 minutes they will need to be told to finish at the completion of the game they are on).

7. A nominated group member will return the HGCs to their containers.

8. A nominated student will ensure that all HGCs are returned. Students will sign that this has been checked.

9. Teacher will store these in a secure cabinet at the end of the session.

\section{During the week}

1. At the beginning of each week the students will set goals for each game they play. These goals will be reviewed at the end of the week. A discussion of how they went and the need to adjust goals should take place. Further, a discussion of how they could improve from the teacher and tips from peers would be worthwhile. This might make up 5/10 minutes on a Friday.

2. At the end of the week students will write down their best time of the week.

3. As the week transpires they might also write down sums they are having trouble with and focus on these for homework.

4. At the end of the week students may test their brain age. 